\title{
A humanização dos serviços e o direito à saúde
}

\author{
Humanization of healthcare services \\ and the right to healthcare
}

\author{
1 Secretaria de Saúde \\ de Itapecerica da Serra, \\ Itapecerica da Serra, Brasil. \\ 2 Faculdade de Ciências \\ Médicas, Universidade \\ Estadual de Campinas, \\ Campinas, Brasil.

\section{Correspondência} \\ P. T. Puccini \\ Secretaria de Saúde \\ de Itapecerica da Serra \\ Av. Piassanguaba 1923, \\ São Paulo, SP \\ 04060-003, Brasil. \\ ppuccini@terra.com.br
}

\begin{abstract}
This article discusses the possibilities and limits of proposals for the humanization of healthcare. The theoretical references utilized are the concept of "reification" as a causative explanation for the process of man's estrangement from his world and the concept of "radical needs" as a possible way of overcoming traditionalist humanism to achieve transformative practice. From these notions, an understanding of the difficulties and contributions of the movement towards humanization is sought, highlighting the interdependence and limits of sectoral changes within healthcare in light of society's concepts and general values. The article concludes by suggesting that guidelines for humanization/satisfaction, in bringing together the critique of society's general questions concerning the daily difficulties of healthcare services, may keep the comprehensiveness of the right to healthcare open beyond the limits of current social relations, thereby favoring a stance that opposes the restrictive trend of minimal public policies towards healthcare.
\end{abstract}

Delivery of Health Care; Public Policy; Right to Health
Paulo de Tarso Puccini 1

Luiz Carlos de Oliveira Cecílio 2

\section{Introdução}

Muitas podem ser as compreensões ou definições de qualidade. Vuori 1 avalia que a noção de qualidade varia com o interesse dos diferentes grupos sociais, que podem ter pontos de vista diferentes sobre o que constitui qualidade. Para Donabedian, a conceituação de qualidade coloca-se como construção de um modelo normativo para avaliar os serviços de saúde, capaz de monitorar e induzir um balanço cada vez mais favorável entre benefícios e riscos. Assim, para esse autor, a qualidade da atenção à saúde se define como um arranjo ideal de um vasto conjunto de elementos presentes na estrutura, no processo e no resultado 2 .

Qualidade é uma aspiração declarada, com distintos objetivos, de empresas privadas e das instituições do setor público, bem como do consumidor de determinado produto. Sempre foi um objetivo a ser alcançado que, na realidade cotidiana do fazer, era modulado pelas possibilidades da ação prática, dos estilos gerenciais e dos interesses de um determinado corpo proprietário ou dirigente.

Entretanto, a partir das formulações da teoria da "Gestão pela Qualidade Total”, a qualidade, em si, vem se afirmando como um conceito paradigmático para a formulação de modelos gerenciais, desenvolvidos como resposta a certas dificuldades das empresas privadas e que, também, são, muitas vezes, transpostos de for- 
ma acrítica para o setor público. Assim, a idéia geral de qualidade como qualificação do fazer, naturalmente expressando diferentes significados conforme a posição social do seu proponente no processo produtivo, estreita-se com o movimento pela “Qualidade Total”, e vai ganhando um sentido mais comprometido e articulado com os interesses do sistema social produtor de mercadorias.

Neste movimento "renovador", os conceitos de qualidade e de satisfação do consumidor parecem ganhar autonomia e potencialidade determinística sobre o fazer. É como se tudo que se pensava ter feito bem, em correspondência a determinadas necessidades, fosse uma ilusão, um turvamento das ações pela presença de outros interesses na organização empresarial (particularmente dos trabalhadores), que impregnavam negativamente os produtos ou os serviços prestados. Não se tinha o êxito almejado na satisfação das necessidades porque não se concentrava e motivava em fazer com qualidade, não se trabalhava adequadamente.

O envolvimento de todos os trabalhadores, um dos princípios fundamentais do modelo de “Gestão pela Qualidade”, é entendido como a busca do alto desempenho da organização, por meio do estímulo à colaboração e ao compromisso dos trabalhadores para atingir objetivos e metas da organização; exemplificando com as proposições do programa brasileiro de qualidade e produtividade “ (...) o agente público $e o$ Estado não se bipartem, sendo a vontade e a ação dos agentes a representação da vontade $e$ da ação do Estado. Essa relação orgânica existente entre organizações públicas e seus servidores/empregados evidencia a importância vital da atenção vigorosa à gestão das pessoas" (p. 56), “ (...) toda organização pública, para atender sua missão, precisa funcionar como um organismo integrado, com todas as suas ações sistematizadas e direcionadas para a consecução de objetivos comuns. De forma geral, a gestão de processos compreende a definição, execução, avaliação, análise e melhoria dos processos organizacionais" (p. 62).

Como afirma Lukács 4 (p. 103): "em conseqüência da racionalização do processo de trabalho, as propriedades e particularidades humanas do trabalhador aparecem cada vez mais como simples fontes de erro, racionalmente calculado de antemão. (...) O homem não aparece, nem objetivamente nem no seu comportamento, em relação ao processo de trabalho como verdadeiro portador desse processo (...)".
Um aspecto característico dessas novas escolas da teoria geral da administração (TGA) é o interesse pelas condições sob as quais o trabalhador pode ser mais bem induzido a cooperar no esquema de trabalho organizado. Amargamente, reclama-se das características de uma população trabalhadora que os próprios "gerentes científicos" modelaram para ajustarse aos seus fins, mas não encontraram, e incessantemente procuram um jeito de produzir trabalhadores que sejam ao mesmo tempo degradados em seu lugar no processo de trabalho e também conscienciosos e orgulhosos de seu trabalho. A qualificação e a competência exigidas pelo capital muitas vezes objetivam de fato a confiabilidade que as empresas pretendem obter dos trabalhadores, que devem entregar sua subjetividade à disposição do capital 5,6.

Discutindo determinados tipos de produção científica, Lukács 4 (p. 22) propõe que " $a$ ciência que reconhece, como fundamento do valor científico, o modo como os fatos são imediatamente dados e, como ponto de partida da conceituação científica, a sua forma de objetividade, esta ciência coloca-se muito simples e dogmaticamente no campo da sociedade capitalista, aceitando sem crítica sua essência, a sua estrutura de objeto, as suas leis, como fundamento imutável da 'ciência”."

Em todo desenrolar das grandes teorias da TGA, a contradição essencial entre capital e trabalho fica oculta mesmo quando questões políticas, como o conflito e o poder, são discutidas 7 . Essa condição não é, portanto, exclusividade desse movimento pela qualidade. A ocultação da realidade concreta, mantida nas sucessivas atualizações da TGA, é elemento indissociável de suas proposições, e essa teoria gerencial da qualidade não foge à regra. Isso não significa que esse movimento não tenha contribuições, algumas de valor operacional considerável, mas sim que a modernização proposta está inapelavelmente reificada pelos valores da sociedade capitalista. Reificação é aqui entendida como a situação resultante do tipo de processo produtivo da sociedade, e por ele caracterizada, sobretudo, no sistema capitalista, em que o trabalho humano, cuja base é uma relação entre pessoas, se realiza de modo que produza coisas que são separadas dos homens, para se transformarem em mercadorias independentes ou imaginadas como tal, que, em vez de serem intermediárias entre indivíduos, convertem-se em realidades soberanas que passam a governar a vida social, submetendo a 
atividade humana que se torna estranha ao próprio homem 4 .

Sugere-se, então, numa aproximação esquemática ao tema da qualidade e dos modelos gerenciais pela qualidade, que, a depender da visão de mundo sob a qual são analisados, podese compreendê-los como uma busca fenomenológica de uma resposta ética ao consumidor, num plano mercadológico; ou como a definição de normas de um padrão-ouro no uso da técnica; ou, ainda, pelo prisma de uma visão contra-hegemônica, buscar criticamente os significados desses temas na relação com a totalidade concreta revelando seus interesses mais profundos, inseridos nos próprios impasses da produção e reprodução do sistema social 8. Com a intenção de uma abordagem crítica, adota-se o caminho metodológico enfatizado por Kosik 9 , segundo o qual, sem a compreensão da realidade como totalidade concreta - que se transforma em estrutura significativa para cada fato ou conjunto de fatos -, o conhecimento da realidade concreta não passa de mística, ou coisa incognoscível em si. A concreticidade não nega o conhecimento da existência ou da objetividade dos fenômenos, mas reconhece que é necessário articulá-los com uma totalidade concreta, para compreendê-los a partir de suas mútuas determinações. A pseudoconcreticidade é justamente a pretensa existência autônoma dos produtos do homem e a redução do homem ao nível da práxis utilitária. A realidade social não é considerada totalidade concreta se o homem, no âmbito da totalidade, é considerado apenas objeto, e se na práxis histórico-objetiva da humanidade não se reconhece a importância primordial do homem como sujeito.

A adoção formal dos conceitos da "Gestão pela Qualidade” no setor público brasileiro teve início com a criação, em 1991, do Programa Brasileiro de Qualidade e Produtividade. Configurou-se como o Programa 2.057 do Plano Plurianual 2000-2003 (http://qualidade.planejamento.gov.br, acessado em 20/Jul/2001). O Departamento Nacional de Auditoria do Ministério da Saúde colocou-se como um núcleo de propagação e organização desse movimento gerencial nos diferentes níveis governamentais do Sistema Único de Saúde (SUS). Esse expressivo movimento de "Gestão pela Qualidade Total”, também presente na área da saúde pública, tem convivido, por vezes de forma complementar e em outras em disputa, com as proposições voltadas para a humanização dos serviços. De fato, algumas características do movimento humanizador o impulsionam para uma possível diferenciação com o ideal da "Qualidade Total”. O movimento pela humanização é, em última instância, também uma busca pela qualificação da produção ou prestação de serviços, mas delineia-se, na sua implementação, uma força e um potencial de crítica e ruptura com um compromisso mercadológico obrigatório de tudo ou, ainda, com uma normalização institucional que diga respeito, apenas, à lógica tecno-burocrática e à busca obtusa pelo desempenho produtivo.

A humanização é um movimento com crescente e disseminada presença, assumindo diferentes sentidos segundo a proposta de intervenção eleita. Aparece, à primeira vista, como a busca de um ideal, pois, surgindo em distintas frentes de atividades e com significados variados, segundo os seus proponentes, tem representado uma síntese de aspirações genéricas por uma perfeição moral das ações e relações entre os sujeitos humanos envolvidos. Cada uma dessas frentes arrola e classifica um conjunto de questões práticas, teóricas, comportamentais e afetivas que teriam uma resultante humanizadora.

Nos serviços de saúde, essa intenção humanizadora se traduz em diferentes proposições: melhorar a relação médico-paciente; organizar atividades de convívio, amenizadas e lúdicas como as brinquedotecas e outras ligadas às artes plásticas, à música e ao teatro; garantir acompanhante na internação da criança; implementar novos procedimentos na atenção psiquiátrica, na realização do parto - o parto humanizado e na atenção ao recém-nascido de baixo peso - programa da mãe-canguru; amenizar as condições do atendimento aos pacientes em regime de terapia intensiva; denunciar a "mercantilização" da medicina; criticar a "instituição total” e tantas outras proposições.

Assim, com as propostas de humanização, cresce uma valorização das inter-relações humanas, como uma trincheira de resistência contra o avassalador convencimento da superioridade moral do mercado, e eleva-se a um valor superlativo a busca da dignidade humana. Por outro lado, seu desenvolvimento fragmentado, segundo diferentes experiências, e o fato de cada um de seus singulares realizadores tentar explicar as dificuldades do mundo com um horizonte de análise reduzido têm colocado as razões e motivações de tal movimento humanizador em caminhos diferentes e até mesmo conflituosos.

\section{Os distintos caminhos das proposições humanizadoras na saúde}

Compilando alguns trabalhos publicados nas revistas científicas da área de saúde - Rocha \& 
Simões 10, Trezza 11, Oliveira 12, Fernandes 13, Manrique \& Altuna 14, Bozzo \& Martínez 15, Santos 16, Aires et al. 17, Montoya 18, Kloetzel et al. 19, Zusman 20, Caprara \& Franco 21, Soares 22, Gallian 23, Ministério da Saúde 24, Zaicaner 25, Martins 26 -, constatam-se algumas direções fundamentais dessa preocupação com a humanização e satisfação do usuário: ora aparece com uma noção de amenização da lógica do sistema social, centrado sobretudo numa crítica à tecnologia e como tentativa de criar um "capitalismo humanizado"; ora como a busca de uma essência humana perdida, ou seja, como um movimento de restauração moral; ora como uma negativa existencialista da realidade concreta, imaginando uma autonomia das emoções e afetividades individuais da práxis humana; ora como processo de organização institucional que valoriza a escuta no ato assistencial; ora como valorização de direitos sociais.

Uma das características mais expressivas desse movimento na área da saúde, sobretudo nas considerações sobre a prática médica, é a crítica à tecnologia. Veja-se um exemplo: "em razão do acelerado processo de desenvolvimento tecnológico em medicina, a singularidade do paciente-emoções, crenças e valores - ficou em segundo plano; sua doença passou a ser objeto reconhecido cientificamente. O ato médico, portanto, se desumanizou" 26 (p. 27).

Na defesa de uma "reumanização" da medicina, outro autor afirma: "os grandes avanços científicos e técnicos no campo das ciências experimentais aplicadas à medicina e às ciências da saúde em geral vêm trazendo uma série de transformações nesses campos. O processo de desumanização é uma das conseqüências do divórcio entre a medicina e as humanidades que ocorreu, principalmente, a partir de fins do século XIX (...) As causas das doenças, portanto, deveriam ser buscadas não apenas no órgão ou mesmo no organismo enfermo, mas também e principalmente no que há de essencialmente humano no homem: a alma, esse componente espiritual que distingue o homem dos outros organismos vivos do planeta" 23 (p. 5). E conclui com atualíssimo tom bucólico: "homem culto, o médico romântico aliava seus conhecimentos científicos com os humanísticos e utilizava ambos na formulação dos seus diagnósticos e prognósticos. Conhecedor da alma humana e da cultura em que se inseria, já que invariavelmente andava muito próximo de seus pacientes - como médico de família que era-, esse respeitável doutor sabia que curar não era uma operação meramente técnica (...)" 23 (p. 6).

Como contraponto a essas idéias, não é demais citar uma aguda observação de $\operatorname{Kosik}^{9}$ (p.
55-6): "o iluminismo elimina a falsa consciência da história e descreve a história da falsa consciência como história de erros que na realidade não deveriam ter ocorrido se os homens tivessem sido mais perspicazes e os soberanos mais sábios; a ideologia romântica, ao contrário, considera verdadeira a falsa consciência porque só ela teve eficácia, efeito, influência prática e, portanto, só ela foi realmente história".

Assim, o caminho proposto de uma "reumanização" da medicina guarda forte apego bucólico, limitando-se à questão da formação médica e seu caráter clássico perdido por força da tecnologia. Reduz a questão a um problema no interior da epistemologia médica, procurando retomar, por meio da volta ao passado, o caráter técnico e moral perdido, restaurando um médico idealizado na literatura romântica. Avalia-se, assim, que essa discussão, sem a devida articulação com a evolução das relações sociais, sem a presença da concepção da totalidade concreta, dos interesses, das classes sociais, da cultura, do Estado moderno, não consegue ultrapassar uma saudade idealizada, uma inconformada racionalidade religiosa perdida.

Após analisar uma variedade de inovações tecnológicas e de automação do trabalho, Braverman 5 conclui que o aspecto unificador é o mesmo: a eliminação progressiva das funções de controle pelo trabalhador, tanto quanto possível, e a transferência desse controle para um dispositivo que é controlado pela gerência externa ao processo imediato. "Não é a força produtiva da maquinaria que enfraquece a espécie humana, mas a maneira pela qual ela é empregada nas relações sociais capitalistas. (...) É, sem dúvida, este 'senhor', por trás da máquina, que domina, drena a força de trabalho viva" 5 (p. 197). Mas, enfatiza o autor, tornou-se elegante atribuir à maquinaria os poderes sobre a humanidade que decorrem, de fato, das relações sociais. A sociedade, segundo esse modo de ver, nada mais é que uma extrapolação de ciência e tecnologia. Esta é a coisificação de uma relação social, um fetichismo, no sentido que Marx dá ao termo.

Com base num enfoque mais psicológico, Zusman 20 (p. 946) diz: "a humanização admite o reconhecimento da realidade interna, implica a aquisição de valores que levam ao refinamento da consciência moral, da sensibilidade ao sofrimento alheio, da compaixão, da capacidade empática, da tolerância ao sentimento de culpa e à consciência da finitude e fragilidade humanas. Implica a admissão estóica ou resignada dos 'sofrimentos intrínsecos ao viver'”.

Proposições como essa reforçam a necessidade de valorizar as questões subjetivas envolvidas, particularmente no processo de realiza- 
ção dos cuidados de saúde. Mas é importante incorporar esse tipo de contribuição sem ultrapassar seu limite de possibilidades, entendendo que os índices de valor com características ideológicas, ainda que exteriorizados por um indivíduo, constituem índices sociais de valor, com pretensões ao consenso social. A consciência adquire forma e existência nos signos criados por um grupo organizado no curso de suas relações sociais. É, portanto, indispensável que o objeto adquira uma significação interindividual; somente então é que ele poderá ocasionar a formação de um signo. Evidentemente, o signo não é determinado pelo arbítrio individual, pois o signo se cria entre indivíduos, no meio social. Eles são o alimento da consciência individual, a matéria de seu desenvolvimento. Como afirma Bakhtin 27 (p. 48), "é impossivel reduzir o funcionamento da consciência a alguns processos que se desenvolvem no interior do campo fechado de um organismo vivo. Os processos que, no essencial, determinam o conteúdo do psiquismo desenvolvem-se não no organismo, mas fora dele, ainda que o organismo individual participe deles. O psiquismo subjetivo do homem não constitui um objeto de análise para as ciências naturais, como se tratasse de uma coisa ou de um processo natural. O psiquismo subjetivo é o objeto de uma análise ideológica, de onde se depreende uma interpretação sócio-ideológica”. “ (...) A realidade ideológica é uma superestrutura situada imediatamente acima da base econômica. A consciência individual não é o arquiteto dessa superestrutura ideológica, mas apenas um inquilino do edifício social dos signos ideológicos. (...) A consciência individual é um fato sócio-ideológico" 27 (pp. 35-6).

É certo que as modificações existenciais contribuem para as mudanças sociais, mas, como afirma Kosik 9 (p. 90), "na modificação existencial o sujeito do indivíduo desperta para as próprias potencialidades e as escolhe. Não muda o mundo, mas muda a própria posição diante do mundo. A modificação existencial não é uma transformação revolucionária do mundo; é o drama individual de cada um no mundo".

\section{Para uma crítica do movimento humanizador}

Será que no decorrer do tempo a espécie humana, envolvida na luta pela sobrevivência, perdeu a sua "essência humana"? O que seria então essa essência? Em que remoto tempo e lugar ela estaria trancada e esquecida, de modo que um mutirão da boa vontade precisasse urgentemente resgatá-la desta situação de re- fém da razão? Seria um novo ribombar do pecado original? Perdemos a fé e estamos pagando pela nossa dissidência com o transcendental? Maltratamos tanto a natureza que acabamos perdendo a noção da nossa própria conduta natural biológica?

Com essas indagações, que são hipóteses explicativas do movimento humanizador, procura-se alertar para uma dificuldade em se conceituar uma avalanche de intenções que, situadas no campo dos justos e politicamente corretos, trabalham com concepções de mundo muito diferentes, resultando em distintas propostas de humanização que, no fundo, só coincidem enquanto slogan de propaganda. Nesse sentido, muitos programas de instituições da área da saúde vêm inserindo atividades sob a denominação do clichê "humanização". Assim, fixados na propaganda dos efeitos de uma situação que é explicada com noções genéricas, que estão mais ao alcance do que as realidades a que correspondem, iniciativas pontuais correm o risco de substituir a totalidade da realidade por essas noções elementares dos fatos, freqüentemente supervalorizados com motivação demagógica. Esse proceder estabelece um novo véu que se interpõe entre a realidade das coisas e os homens, mascarando-a, bem como às condições determinantes daquilo que se pretende mudar 28. Ou, ainda, essa significação social do movimento humanizador, com base em somatório de fatos, resulta na sobreposição fenomenológica da aparência à essência das coisas, pela perda do sentido da totalidade concreta como estrutura significativa para cada fato ou conjunto de fatos 9 .

Esse movimento de exigência de humanização das atividades humanas não é, absolutamente, novidade na área da saúde nem na sociedade em geral. Ele expressa o estranhamento do homem diante de seu mundo. Entretanto, embora isso seja rotineiro, é interessante observar o alto risco de seu tom discursivo redundante, tal como de um culto religioso, pois já sendo as ações humanas (sejam elas julgadas boas ou más) pertencentes ao homem, por que então falar em humanizá-las? Para explicar esse paradoxo, é necessário cautela para não valorizar as subjetividades abusivamente, ultrapassando o alcance de sua potência transformadora e produzindo uma "psicologização" do processo social. Konder 29, discutindo aspectos da alienação, afirma que o refúgio na vida privada não impede que a dilaceração do humano sacrifique a unidade e promova a confusão. O mundo psíquico atomiza-se tanto quanto o social e perde o sentido da totalidade, e este choque é inautenticamente vivido sob a for- 
ma caricatural de um conflito entre a "razão e os sentimentos", como uma manifestação da cisão entre o singular e o universal, entre os indivíduos e a espécie no interior dos indivíduos. Assim, sem a percepção do que há de comum com os outros, as diferenciações individuais passam a ser observadas independentemente da história concreta e das condições materiais de vida dos homens.

Nessa diversidade conceitual de intenções e motivações, cresce uma tendência a se considerar a concretização da humanização e suas possibilidades de alcance como um processo dependente da incorporação de algo trazido de fora do homem como ser social, quer pela noção de Deus como origem ou fonte de uma essência perdida, quer da natureza com seus instintos racionais de qualidade, quer pelo resgate de uma essência humana eterna e imutável inerente a todos os indivíduos da espécie. $\mathrm{O}$ que têm em comum esses três caminhos é a resposta a problemas reais, com base em diagnósticos causais e soluções que diluem o caráter histórico-social tanto dos problemas como da própria idéia de humanização. Isto é, o entendimento da humanização como um aspecto da realidade humana mutável com o tempo, tal como o homem, que, por sua natureza histórica e social, é um ser cuja "característica é a de estar se fazendo ou se autoproduzindo constantemente tanto no plano de sua existência material, prática, como no de sua vida espiritual, incluída nesta a moral" 30 (p. 25).

Mas, afinal, o que significa a idéia de humanizar diferentes aspectos da vida social e das ações de saúde em particular? Para responder a essa questão, é preciso optar por um entendimento desse movimento humanizador que procure articular coerentemente, numa perspectiva transformadora, tudo o que haja de positivo em cada uma das inúmeras novas experiências e contribuições em diferentes atividades. A primeira tentação é dar por resolvida essa insuficiência, reafirmando a definição genérica do humanismo clássico entendido como qualquer atitude ou teoria que afirme que a dignidade humana é o valor supremo e deve, portanto, ser tão favorecida quanto defendida dos ataques procedentes dos poderes políticos, econômicos e religiosos. Mas essa definição implica uma definição preliminar do homem (de uma essência do homem anterior à sua existência prática), o que pode acarretar paradoxalmente a exclusão de certos seres humanos da humanidade no sentido nobre. Por isso, em defesa do ser humano, o humanismo tradicional foi tão atacado por propostas filosóficas que "podem ser indiferentemente qualificadas de anti-humanismo - pelo fato de recusarem a situação à qual o homem chega historicamentee de humanismo - pelo fato de proporem um devir mais digno para o ser humano" 31 (p. 233).

Não se adotou, neste trabalho, o entendimento de humanização como busca da "essência humana” perdida. Optou-se pela conceituação que compreende a essência humana não como algo abstrato e imanente a cada indivíduo ou como algo universal que se manifestaria nos indivíduos, mas como o conjunto das relações sociais. Não é no indivíduo que podemos encontrar a essência humana, mas sim nas relações sociais, das quais ele mesmo é um produto. Assim, a essência humana passa a ser compreendida como algo que só pode ser desvendado no conjunto das relações sociais, que produzem tanto a natureza do homem social como a de indivíduos, pois o indivíduo à margem dessas relações é uma abstração, e a essência humana, concebida como atributo individual, é tão abstrata quanto ele 32 .

A essência humana, portanto, não é o que "esteve sempre presente" na humanidade, mas a realização gradual e contínua das possibilidades imanentes à humanidade, dos valores próprios do gênero humano, como o trabalho, a socialidade, a universalidade, a consciência e a liberdade. A expressão e a hierarquia dos valores explicitam ou são as condições de explicitação, em cada época, de uma determinada essência humana 33 .

A liberdade do homem e a produção do mundo humanizado são, por conseguinte, a consciência histórica da necessidade, mas não se reduzem a isso, não se reduzem a transformar a escravidão espontânea e cega numa escravidão consciente de necessidades, não são assunto apenas teórico, pois estão ligadas ao desenvolvimento do homem como ser prático, transformador ou criador de um devir mais digno para o ser humano contextualizado e capaz de recusar a passividade ante o reino das necessidades "necessárias" 32.

O homem, este ser sócio-histórico, tem a capacidade de objetivar suas carências e poderes no processo de sociabilidade e historicidade; assim, em cada objeto concreto, condensa os processos de trabalho como processos de reprodução social 34 . Marx 35 (p. 40) enfatiza a compreensão da produção histórica das necessidades: “(...) satisfeita esta primeira necessidade, a ação de satisfazê-la e o instrumento de satisfação já adquirido conduzem a novas necessidades - e esta produção de novas necessidades é o primeiro ato histórico".

A espiral desse processo vai estabelecendo, em cada período, em cada sociedade e em ca- 
da grupo de homens ou classes dessa sociedade, de modo sempre dinâmico, um conjunto de necessidades que se costuma denominar de necessidades “necessárias”. Essas são, portanto, históricas. São sempre conscientes uma vez que individuais, embora sócio-historicamente produzidas.

Prisioneiros das necessidades "necessárias", os homens alienaram-se ao domínio das coisas sobre eles, quando as relações inter-humanas aparecem como relações entre coisas, e as necessidades não são governadas pelas necessidades de desenvolvimento e auto-realização do indivíduo 36. Essa condição permite compreender a alienação do homem como fato intrínseco da ação reificadora das relações sociais capitalistas, fonte primeira deste estranhamento, produzida e reproduzida pelo sistema nos diferentes campos da vida social. Assim, é que o movimento da "Qualidade Total" fixa um compromisso intrínseco de uma metodologia operativa com o sistema produtor de mercadorias em correspondência às chamadas necessidades "necessárias".

Portanto, o que importa sobre o movimento humanizador, como contribuição para o provimento de necessidades, não é julgar seu status moral ou seu grau de compromisso com uma eficiência operacional dirigida pelas "necessidades necessárias”; o que está em jogo é a finalidade, o potencial e a direção desse movimento para o enriquecimento humano capaz de colocar socialmente em questão as amarras culturais, sociais, políticas e econômicas que travam a conquista de novos padrões universais e solidários de qualidade de vida 36 .

Para tanto, seria oportuno introduzir o conceito de necessidades radicais que, segundo Heller 36, não deixam de ser partes da constituição orgânica das necessidades "necessárias" do corpo social do capitalismo, mas sua satisfação é impossível dentro desta sociedade e, precisamente por isso, motivam a práxis que transcende a sociedade que as determina. Não são sonhos ou receitas morais utópicas, pois têm origem nos próprios conflitos e insuficiências da estrutura das necessidades "necessárias". Destacam-se do conjunto dessas necessidades sócio-historicamente produzidas, objetivadas, conscientes, individuais, como um subconjunto com essas mesmas características, mas que se opõem, porque opõem seus portadores ao modo de reprodução histórica da sociabilidade. Configuram, para seus portadores, a efetivação das possibilidades imanentes de “enriquecimento humano" e expansão como sujeitos de forma congruente com sua gênese e diferenciação. Expressam a busca de confluên- cia entre causalidade (objetividade das coisas e das "circunstâncias") e teleologia (as finalidades a que aspiram os homens) e exigem a remoção dos obstáculos sócio-históricos à sua satisfação 34,36. Ou seja, não é na dimensão interna do trabalho morto, das tecnologias e sua causalidade implícita que uma necessidade se torna ou não radical, no sentido proposto. Para tal confluência, exige-se a expressão dos sujeitos coletivos, de suas finalidades postas como questionamentos à ordem das coisas e como constituição do bloco de forças capaz de encaminhar as mudanças exigidas.

As necessidades radicais não são nem mais nem menos verdadeiras ou reais do que as necessidades "necessárias", mas encarnam o questionamento aos limites de progresso imposto pelo conjunto das relações sociais numa dada formação social, econômica e política. Esta potencialidade de ruptura e de geração de forças sociais pela mudança estabelece sua vinculação prática com um processo político radical e de ampla participação pela transformação da ordem vigente.

\section{Possibilidades e limites do movimento de humanização na saúde}

Optou-se, neste trabalho, por ancorar a discussão do movimento de humanização na saúde, apesar das distintas visões existentes, com a idéia apresentada das necessidades radicais. Isto é, uma opção de entendimento que transforma a doutrina humanista clássica atravessando-a com o pulsar histórico dos carecimentos humanos concretos construídos socialmente.

Assim, tal movimento ganha característica de práxis humana radical, e não apenas uma existência no campo das predicações morais. Recusou-se, assim, o entendimento da humanização limitada a uma coletânea de ações para a amenização das contradições sociais. Este caminho não difere do movimento da "Qualidade Total" e não traz nada de novo em relação a ele, acrescentado apenas um toque romântico e sensível no seu proceder.

Articulando o movimento humanizador na saúde com a questão do reconhecimento e da valorização social das necessidades radicais, concebe-se uma linha de identidade das diferentes experiências desse movimento como tentativas de rupturas, de ir além das necessidades "necessárias", de valorizar a autonomia dos sujeitos e as diferenças. Compreende-se o imperativo da incorporação do outro, segundo seu patamar real de acesso aos bens materiais e culturais, com a humildade de ponderar as 
verdades tecno-científicas. Abandona-se o foco da preocupação epistemológica de construção de uma ciência isenta, neutra e reconciliada internamente com o humanismo clássico, para se procurarem respostas no processo social e político dialógico entre os sujeitos. Abandonam-se os nobres e elevados horizontes de compreensão do mundo e dos valores morais, recitados religiosamente, para recolocá-los segundo os limites da vida real, das condições cruentas e primárias da sobrevivência material, cultural e moral dos homens, segundo as diferentes vivências da alienação, das desigualdades sociais e da sua reprodução sistêmica.

Na perspectiva dessa práxis transformadora, ganha importância a relação entre profissionais de saúde e usuários: passagem do ambiente relacional de individualismos com individualismos para o ambiente relacional de sujeitos sociais com sujeitos sociais. Isto é, o subjetivo extravasa o plano dos afetos íntimos, sem abdicar dele, e ganha, também, significado e expressão como parte integrante de um projeto social e de seus objetivos. Na área da saúde, a perspectiva da conquista social do direito à saúde constitui a busca de um estágio mais avançado de autonomia, definido como capacidade das pessoas de não apenas eleger e avaliar informações com vistas à ação, mas de criticar e, se necessário, mudar as regras e práticas da sociedade a que pertencem 37 .

No ato de reconhecer e valorizar as necessidades radicais está a fundamental diferença entre o provimento mínimo e o básico do direito à saúde, momento no qual se constituem as alianças sociais na defesa para que o alcance e a abrangência das políticas públicas não sejam reduzidos ao mínimo. O ótimo no provimento de um direito social é, certamente, um ponto sempre em fuga, mas o mínimo e o básico não são a mesma coisa; do ponto de vista prático, conceitual e político, são noções assimétricas. O mínimo tem o significado de menor, de menos, identificado com patamares de satisfação de necessidades que beiram a desproteção, acompanhado por supressão ou cortes de atendimentos. Já o provimento do básico expressa algo fundamental, principal, primordial, que serve de base de sustentação indispensável ao que a ela se acrescenta. O básico requer investimentos sociais de qualidade que preparem o terreno para o surgimento de outras necessidades, que questionem os limites da própria estrutura social e das relações sociais vigentes 38 .

À medida que o movimento pela humanização se eleva da predicação moral para uma preocupação operativa do direito à saúde, com a reorganização dos serviços e das práticas em saúde, ele incorpora de maneira simbiótica a categoria da satisfação dos usuários. A novidade característica da humanização/satisfação radical é, portanto, a possibilidade de abrir a organização para o cidadão indo além da mensuração de graus quantitativos de satisfação, incorporando a opinião e reivindicações da população neste processo de mudanças e contribuindo para uma tomada de consciência mútua dos profissionais e cidadãos de novas finalidades e projetos comuns para a saúde 8 .

A humanização, esvaziada desses conteúdos, restringe os sentidos e as conseqüências da sua ação operacional ao limite da metodologia da "Qualidade Total” com sua preocupação restrita, focada internamente na organização, nos seus processos e no exercício da modulação organizacional, segundo as necessidades "necessárias”. Assim, o movimento da humanização também aparece restrito, focado na organização, exaltando conhecimentos, técnicas e habilidades interacionais dos profissionais. Nesse caso, apesar de alguma diferença vernácula, se tal preocupação não encontrar um fundamento mais amplo e aberto, poderá limitar-se ao mesmo horizonte do movimento da qualidade. Reconhece-se que isso, sem dúvida, já é um ganho em relação ao rígido fechamento da organização para o seu ambiente de atuação, mas representa o abandono de uma visão mais ampliada e potencialmente emancipadora.

O movimento da humanização radical tem natureza mais flexível, pois está focado para além da qualificação. $\mathrm{O}$ ir além da qualificação do fazer numa estrutura social fixada representa a dimensão característica do movimento radical de humanização e satisfação. Essa característica condiciona e limita o alcance autônomo desse movimento, pois ele não se resolve nos limites setoriais, exigindo um projeto político-social amplo.

\section{Humanização radical e o direito à saúde}

As novas condições para a organização das ações de saúde no Brasil, concretizadas com a regulamentação do SUS, na Constituição de 1988 e na legislação ordinária que se seguiu (Lei 8.080/90 e Lei 8.142/90), inauguraram um novo ciclo de disputas, qualitativamente distinto das questões e problemas que tomavam conta da agenda político-social da área da saúde, no período anterior. A saúde como direito social é a mudança fundamental anunciada pelo SUS. A reconstrução do sistema de saúde em novas bases, portanto, não é tarefa simples, pois ultrapassa um questionamento conceitual 
interno da área, restrito apenas aos seus técnicos e profissionais. Assim, para a sua consolidação, torna-se gradativamente insuficiente apenas o posicionamento crítico em relação ao conceito limitado da saúde ou em relação à forma de organização dos serviços - dicotomizada entre as ações individuais e as coletivas e entre prevenção e cura, características da situação anterior. A nova arena exige mais. Tomando a conceituação ampla sobre a saúde, a nova arena exige que se criem formas que materializem social e politicamente uma ação cuidadora integral, como direito de cidadania.

No processo de busca da superação do modelo médico-privatista e da saúde pública campanhista e controlista enfrentam-se polêmicas recorrentes com as concepções restritivas representadas pelas propostas de provimento mínimo do direito à saúde, focadas na rede básica simplificada, com equipe mínima, cumpridora de uma "oferta organizada" unilateral e "tecnicamente" definida, oriundas da concepção da “atenção primária à saúde” e, também, com as concepções da "Gestão pela Qualidade" que, comprometida com a funcionalidade do "Estado Gerencial", tende a dissolver as arenas de disputa política pela abrangência dos direitos sociais e pela qualidade de vida. Segundo Oliveira 39 , os defensores da crise atual do Estado não propõem o desmantelamento total da função do fundo público como antivalor. O que propõem é a destruição da regulação institucional com a supressão das alteridades entre os sujeitos sócio-econômico-políticos. Ao contrário das teses de que o "tamanho" do Estado, aparentemente, pode ter chegado a limites que ameacem a acumulação de capital, o que está em jogo é exatamente a disputa dos lugares de utilização e distribuição da riqueza pública.

Assim, é necessário reconhecer que há uma integração entre as ações realizadas na esfera pública e a lógica do sistema social e sua reprodução, mas, também, que a luta social tem conquistado a ampliação da ação pública na prestação de serviços sociais, segundo princípios do bem comum, como "antimercadorias e antivalores", a despeito dos interesses imediatos do capital 5,39. Essa situação, sempre muito instável e cheia de avanços e reveses, apresenta-se nos dilemas e dificuldades da implementação do SUS, na disputa pelo provimento mínimo versus o básico do direito à saúde, na disputa pelos fundos públicos. Isto é, a ética do direito à saúde abrangente e radical é, no seu âmago, antagônica à lógica social de funcionamento do sistema capitalista.

Nessas condições, é ainda mais decisiva a questão da finalidade do processo de trabalho nos serviços públicos de saúde, pois os valores da ordem social do sistema estão cotidianamente disputando com os valores contra-hegemônicos do bem comum, do interesse geral. Essa disputa é fundamento para viabilizar o SUS, segundo os princípios do direito à saúde e, também, determinante na desalienação do trabalho dos servidores públicos e na renovação do processo de trabalho de forma conjunta com os usuários. Sugere-se, assim, que essa disputa social e política, ampla e difusa, é uma questão imprescindível, particularmente nesse setor, para uma renovação do processo de trabalho, o qual não pode operar essa mudança radical com um foco exclusivo nas discussões e mudanças tecnogerenciais limitadas a reformas das "direcionalidades" tecnológicas, do como organizar a assistência.

Uma mudança na saúde, ainda que setorial, está de forma permanente interagindo e dependente da disputa dos valores gerais na sociedade na qual se insere. Isto é, novos fins do trabalho em saúde no setor público, sob a ótica do direito social, só encontram sua afirmação democrática com a incorporação do cidadão na definição de projetos, na afirmação do tipo de sociedade que se deseja, na ação política como materialização das possibilidades de gestação de projetos de interesse geral.

Para todos os que têm difundido proposições humanizadoras, há uma intenção de debater e influenciar os rumos desse movimento, disputando a direção das transformações na área da saúde. Assim, esse movimento humanizador tende a ganhar musculatura, exercitado pela crise real do estranhamento do homem diante de seu mundo, que, em suas linhas gerais e pouco precisas, ele denuncia. Seus diferentes proponentes estão construindo esse movimento, são parte dele e nele disputam suas concepções de mundo.

Essa é uma tendência particularmente forte na área da saúde pelas suas características próprias. Toda a assistência se funda numa inter-relação pessoal muito intensa. A saúde, mais do que outros serviços, depende de um laço interpessoal particularmente forte e decisivo para a própria eficácia do ato. $\mathrm{O}$ usuário é um fornecedor de valores de uso substantivos, de tal modo que ele é co-partícipe do processo de trabalho e co-responsável pelo êxito ou malogro da ação terapêutica 40 . Trata-se, portanto, de entender a relação sujeito-objeto como uma relação cognitiva, em que o sujeito e o objeto se determinam mutuamente, se modificam reciprocamente, se transformando no processo 41.

Na dimensão da organização dos serviços e das práticas, os princípios do SUS, em especial 
o da integralidade das ações, são qualificadores do direito social, são elementos que impulsionam a expressão de novas necessidades. Isto é, se no plano mais geral da política o embate dos projetos da saúde concentra-se na disputa pelos princípios da universalidade, da autonomia crítica do controle social, da formatação da eqüidade e da conseqüente política de financiamento do sistema; no plano da organização cotidiana dos serviços e das práticas, é sobre a integralidade do cuidado que se trava a disputa entre o mínimo e o básico.

Assim, sugere-se que, sob a influência do movimento de humanização, a integralidade assistencial pode ser desenvolvida não, apenas, como superação de dicotomias técnicas entre preventivo e curativo, entre ações individuais e coletivas, mas como valorização e priorização da responsabilidade pela pessoa, do zelo e da dedicação profissional por alguém, como outra forma de superar os lados dessas dicotomias. Isto é, a humanização induz a pensar que não é possível equacionar a questão da integralidade sem valorizar um encontro muito além de soluções com modelos técnicos de programação de "oferta organizada" de serviços.

A integralidade do cuidado deixa de ser, portanto, uma simples junção técnica das atividades preventivas e curativas, individuais e coletivas. Os diferentes saberes e práticas, o cuidado e a atenção dispensados a uma pessoa pelos profissionais de saúde são necessários para a sua realização. A integralidade, para concretizar-se, depende do reconhecimento e da valorização do encontro singular entre os indivíduos, que se processa no necessário convívio do ato cuidador. Esse reconhecimento espalha-se como rastilho de afetividades e de necessidades radicais dos indivíduos, contaminando a atmosfera tonal do convívio cotidiano com uma nova força estruturante e de defesa dos princípios do direito à saúde. Integralidade e cuidado reúnem, portanto, em um mesmo novo princípio, uma nova tendência de reconhecimento do outro, um direcionamento da materialização do direito à saúde que não é mais a simples soma aritmética de aspectos técnicos das ações de saúde 8 .

\section{Conclusões}

"Já lhe dei meu corpo, minha alegria; já estanquei meu sangue quando fervia; olha a voz que me resta; olha a veia que salta; olha a gota que falta pro desfecho da festa; por favor; deixe em paz meu coração; que ele é um pote até aqui de mágoa; e qualquer desatenção, faça não; pode ser a gota d'água" (Chico Buarque, Gota d'Água).

Num mundo de muitos potes de mágoa e sofrimentos, qualquer desatenção, particularmente, quando o assunto é o próprio corpo, a própria vida, torna-se de forma abrupta uma questão agressiva. A tensão entre o geral e o particular desaba sobre o convívio singular dos atos cuidadores, e os afetos tornam-se reativos diante do estranhamento que todos vivem. São cúmplices e ao mesmo tempo vítimas insatisfeitas com a situação diuturnamente reproduzida. Reconhecida essa situação, resta saber que tipo de projeto aquela gota a mais do cotidiano dos convívios vai detonar. Individualista, mesquinho, insensatamente agressivo ou coletivo e solidário? Conformista, demagogicamente reparador de conflitos, ou transformador?

Um dos momentos que exige uma resposta rápida, sob pena de implodir o SUS e com ele o direito à saúde, é certamente o desencontro, o descrédito e a desconfiança dos usuários em relação aos serviços públicos de saúde. Essa situação corrói a base de sustentação do SUS, para contentamento dos inimigos da saúde como direito social. É um momento de inflexão no qual todos os defensores do SUS, em especial os envolvidos na sua organização, têm que demonstrar que o direito à saúde é para os homens, e não para a racionalização do Estado. Como afirma Fleury 42, expondo um dos grandes desafios na construção do SUS: evitar que as perspectivas da reforma sanitária sejam filtradas pelo Estado apenas nos aspectos racionalizadores dessa proposta, minando a sua base política, é o dilema reformista, "enigma que poderá ser decifrado a partir da afirmação da saúde como núcleo permanentemente subversivo da estrutura social, o que indica uma possibilidade sempre inacabada no processo de construção social" 42 (p. 45).

Será a concepção teórico-prática da humanização/satisfação radical uma via para contribuir na afirmação da saúde com essas características? Este artigo procurou problematizar em que medida uma diretriz de humanização e satisfação pode contribuir ao aproximar as referências do interesse geral com a reflexão crítica e com a ação sobre as dificuldades cotidianas existentes nos serviços de saúde. Assim, a humanização radical pode criar possibilidades de induzir transformações, mobilizar para novas questões e reconhecer novas necessidades, mantendo em aberto a abrangência do direito à saúde e orientando-o para além dos limites da própria estrutura social e das relações sociais vigentes. 


\section{Resumo}

O artigo discute as possibilidades e limites das proposições humanizadoras na área da saúde. Utiliza como referências teóricas o conceito de "reificação" como explicação da determinação do processo de estranhamento do homem com seu mundo e o de "necessidades radicais" como possibilidade de superação de um humanismo tradicionalista para uma práxis transformadora. A partir dessas concepções, procura-se entender as dificuldades e as contribuições do movimento pela humanização, destacando-se a interdependência e os limites das mudanças setoriais na área da saúde frente às concepções e valores gerais da sociedade. Finalizando, o artigo sugere que uma diretriz da humanização/satisfação, ao aproximar a crítica sobre questões gerais da sociedade às dificuldades cotidianas dos serviços, pode manter em aberto a abrangência do direito à saúde para além dos limites das relações sociais vigentes, favorecendo uma contraposição à tendência restritiva das políticas públicas mínimas na área da saúde.

Prestação de Cuidados de Saúde; Política Social; Direito à Saúde

\section{Colaboradores}

P. T. Puccini realizou pesquisa bibliográfica e elaborou o artigo. L. C. O. Cecílio realizou revisão crítica do artigo.

\section{Referências}

1. Vuori, H. A qualidade da saúde. Revista Divulgação em Saúde para Debate 1991; 3:17-25.

2. Oliveira CG. Breve análise da categoria de satisfação na obra de Donabedian [Dissertação de Mestrado]. Rio de Janeiro: Universidade do Estado do Rio de Janeiro; 1991.

3. Ministério do Planejamento, Orçamento e Gestão. Programa da qualidade no serviço público: instrumento de avaliação da gestão pública. Brasília: Ministério do Planejamento, Orçamento e Gestão; 2001.

4. Lukács G. História e consciência de classe. Porto: Publicações Escorpião; 1974.

5. Braverman H. Trabalho e capital monopolista: a degradação do trabalho no século XX. São Paulo: Livros Técnicos e Científicos; 1987.

6. Antunes R. Os sentidos do trabalho - ensaio sobre a afirmação e a negação do trabalho. São Paulo: Editora Boitempo; 2000.

7. Cecílio LCO. Contribuições para uma teoria da mudança do setor público. In: Cecílio LCO, organizador. Inventando a mudança na saúde. São Paulo: Editora Hucitec; 1994. p. 235-334.

8. Puccini PT. Limites e possibilidades de uma proposta de humanização dos serviços públicos e satisfação dos usuários na luta pelo direito à saúde [Dissertação de Mestrado]. Campinas: Faculdade de Ciências Médicas, Universidade Estadual de Campinas; 2002.

9. Kosik K. Dialética do concreto. São Paulo: Paz e Terra; 1995

10. Rocha JSY, Simões BJG. Avaliação de assistência médica baseada na opinião dos pacientes. Medicina (Ribeirão Preto) 1986; 19:89-98.

11. Trezza EMC. Humanização do atendimento à criança. J Pediatr (Rio J) 1987; 63:218-20.

12. Oliveira CG. Introdução à crítica das noções empregadas em pesquisa sobre "satisfação do usuário”. Saúde em Debate 1990; 30:32-4.

13. Fernandes JCL. A quem interessa a relação médico-paciente? Cad Saúde Pública 1993; 9:21-7.

14. Manrique JL, Altuna IMR. Encuesta de satisfacción de los usuários de um hospital público: medida de la calidad de la atención médica. Rev Argent Cir 1994; 67:189-95.

15. Bozzo SG, Martínez OB. Desarrollo y validación de una encuesta para evaluar la satisfacción de los pacientes con la consulta médica en consultorios de atención primaria. Rev Med Chil 1995; 123:1160-4.

16. Santos MP. Avaliação da qualidade dos serviços públicos de atenção à saúde da criança sob a ótica do usuário. Rev Bras Enfermagem 1995; 48:109-19.

17. Aires IC, Venuto A, Batista CC. O programa de implantação do SUS em Minas Gerais: modalidade de atenção, participação dos usuários, acesso aos serviços de saúde e grau de satisfação. Revista de Administração Pública 1996; 30:5-18.

18. Montoya AC. Participación, salud y sociedad. Cuad Med Soc 1996; 37:33-6.

19. Kloetzel K, Bertoni AM, Irazoqui MC, Campos VPG, Santos RN. Controle de qualidade em atenção primária à saúde. I - A satisfação do usuário. Cad Saúde Pública 1998; 14:623-8. 
20. Zusman W. Pode a psicanálise oferecer algo na preservação do humano? Rev Bras Psicanal 1998; 32:945-51.

21. Caprara A, Franco ALS. A relação paciente-médico: para uma humanização da prática médica. Cad Saúde Pública 1999; 15:647-54.

22. Soares CER. Humanização da medicina. An Acad Nac Med 1999; 159:53-9.

23. Gallian DMC. A (re)humanização da medicina. Psiquiatria na Prática Médica 2000; 33:5-8.

24. Ministério da Saúde. Programa nacional de humanização da assistência hospitalar. Brasília: Ministério da Saúde; 2001.

25. Zaicaner R. Satisfação da clientela: um objetivo a ser alcançado pelo serviço público de saúde [Dissertação de Mestrado]. São Paulo: Faculdade de Saúde Pública, Universidade de São Paulo; 2001.

26. Martins MCFN. Humanização da saúde. Ser Médico 2002; (18):27-9.

27. Bakhtin M. Marxismo e filosofia da linguagem. São Paulo: Editora Hucitec; 1999

28. Durkheim E. O que é um fato social? In: Durkheim $\mathrm{E}$, organizador. As regras do método sociológico. São Paulo: Abril Cultural; 1978. p. 87-109.

29. Konder L. Marxismo e alienação. Rio de Janeiro: Civilização Brasileira; 1965.

30. Vázquez AS. Ética. Rio de Janeiro: Civilização Brasileira; 1995.

31. Durozoi G, Roussel A. Dicionário de filosofia. Campinas: Papirus Editora; 1996.

32. Vázquez AS. Filosofia da práxis. Rio de Janeiro: Paz e Terra; 1990.

33. Heller A. O cotidiano e a história. Rio de Janeiro: Paz e Terra; 2000.
34. Mendes-Gonçalves RB. Práticas de saúde: processos de trabalho e necessidades. São Paulo: Centro de Formação dos Trabalhadores em Saúde, Secretaria Municipal da Saúde de São Paulo; 1992. (Cadernos CEFOR 1, Série Textos).

35. Marx K. A ideologia alemã. São Paulo: Editora Hucitec; 1993.

36. Heller A. Teoría de las necesidades en Marx. Barcelona: Península; 1978.

37. Sposati A, Lobo E. Controle social e políticas de saúde. Cad Saúde Pública 1992; 8:366-78.

38. Potyara APP. Necessidades humanas: subsídios à crítica dos mínimos sociais. São Paulo: Cortez Editora; 2000

39. Oliveira F. Os direitos do antivalor: a economia política da hegemonia imperfeita. Petrópolis: Editora Vozes; 1998.

40. Nogueira RP. O trabalho em serviços de saúde. In: Santana JP, organizador. Desenvolvimento gerencial de unidades básicas do Sistema Único de Saúde. Brasília: Organização Pan-Americana da Saúde; 1997. p. 129-36.

41. Donato AF. Traçando redes de comunicação: releitura de uma práxis da educação no contexto da saúde [Tese de Doutorado]. São Paulo: Faculdade de Saúde Pública, Universidade de São Paulo; 2000 .

42. Fleury S. Reflexões teóricas sobre democracia e reforma sanitária. In: Fleury S, organizador. Reforma sanitária em busca de uma teoria. São Paulo: Cortez Editora; 1995. p. 17-59.

Recebido em 19/Set/2003

Aprovado em 05/Mai/2004 